\title{
PERFORMANCE STUDY ON DIESEL ENGINE BY USING WASTE CHICKEN FAT BIODIESEL
}

\author{
Jaikumar $^{1}$, Veerbhadrappa ${ }^{2}$, Sharanappa Godiganur ${ }^{3}$ \\ ${ }^{1}$ Research scholar RITM Bengaluru-560064 \\ ${ }^{2}$ Research scholar REVA University Bengaluru -560064 \\ ${ }^{3}$ Professor and $R \&$ D Coordinator, School of Mechanical Engineering REVA University, Bengaluru-560064
}

\begin{abstract}
Alternative renewable fuels are being developed and studies are being performed for its better performance and emission controls to replace the conventional petroleum based fuel over a period of time. The chicken fat oil has high viscosity, which leads to problem in pumping and spray characteristics. The inefficient mixing of chicken fat oil with air contributes to incomplete combustion. The use of chicken fat oil as fuel in compression ignition (CI) engines is to convert it into biodiesel. The main resources for biodiesel production can be non-edible oils obtained from plant species such as mahua, jotropha, neem and honge. Different blends of biodiesel can be formulated or a pure form of biodiesel can be used in CI engines with minor engine modifications. Biodiesel can be used in its pure form or can be blended with diesel to form different blends of biodiesel. This paper presents the results of the performance study carried out on biodiesel processed from waste chicken fat in a single-cylinder, four stroke, direct-injection and compression ignition engine. The performance and emission parameters of chicken fat biodiesel blend were found to be very close to neat diesel fuel. Significant improvement in engine performance characteristics was observed for $20 \%$ blend. The biodiesel emissions at $20 \%$ blend are less when compared to pure diesel fuel emissions.
\end{abstract}

Keywords - Chicken Fat Biodiesel, Performance, Emissions, Transesterification.

\section{INTRODUCTION}

Biodiesel provides better lubrication to the engine than petroleum-based diesel fuel and has excellent solvent properties. In this paper, biodiesel produced from renewable sources which meet ASTM International D6751, which is globally recognized standard for biodiesel. B20 is the lowest amount of biodiesel blend allowed for compliance with the Energy Policy Act of 1992 (EP Act). A device which uses B20 includes compression-ignition (CI) engines, fuel oil and heating oil boilers, and turbines. Fuel with higher blend level requires special handling or equipment modifications. Nonedible oils as a substitute for diesel except Jatropha and Karanja. Investigators have already obtained biodiesel from some of these oils $[1,2,3]$

Rapeseed oil is used in Europe as the most common feedstock of biodiesel and likewise soybean oil in the United States of America [4]. Chicken fat is economically low cost raw material for biodiesel production. After rendering process of chicken, chicken waste including chicken feathers, blood, offal and trims are used for biodiesel production $[5,6]$. Soaps are produced from the reaction with alkaline as a catalyst in fat with high free fatty acid (FFA). Which prevent the separation of the ester, glycerin, and wash water [7].

\section{MATERIALS AND METHODS}

The chicken waste from a slaughter house is preprocessed by washing and cleaning with water and made free from flesh and skin. Then chicken fat was melted at around $60^{\circ} \mathrm{C}$ and above. The fat was further filtered to remove suspended particles. To prevent oxidation of the preprocessed chicken fat it was stored in air tight box. The chicken fat FFA was determined and found to be less than $2 \%$.

\subsection{Transesterfication Process}

Pre-esterification process for chicken fat with acid value of less than $2 \%$ is not required for biodiesel production for chicken fat transesterification, so base catalyzed transesterification is used for production of chicken fat biodiesel. The parameters such as methyl alcohol to chicken fat oil molar ratio, catalyst quantity, reaction time and temperature were analyzed. Experiments were conducted to determine the above parameters with a set-up of $1000 \mathrm{cc}$ glass flasks with air tight caps, water cooled condenser which helps in condensing the vapors of $\mathrm{CH}_{3} \mathrm{OH}$ to the reacting mixture and the magnetic stirrer is used to stir the mixture. The flasks were kept on a hot plate maintained at $60^{\circ} \mathrm{C}$, just below the boiling point $\mathrm{CH}_{3} \mathrm{OH}$. Progress of the reaction was monitored at different intervals of time for methyl esters, and diesel.

\subsection{Alkali Catalyzed Transesterification}

The filtered chicken oil is heated for $75^{\circ} \mathrm{C}$. In a beaker add $30 \%$ methanol by weight and $.375 \% \mathrm{KOH}$ (potassium hydroxide) pellets and allow it to dissolve. Transfer the heated oil to the round bottom flask of the esterification setup as shown in the Figure 1. Slowly add the methanol and $\mathrm{KOH}$ mixture to the beaker to the heated chicken oil through side neck. The magnetic stirrer speed is maintained to $900 \mathrm{rpm}$, it stirs the mixture of oil, and methanol and $\mathrm{KOH}$, thereby does 
not allow the mixture to solidify. The stirring is carried on for 60-90 minutes. The condenser does not allow to evaporate the methanol.

In a test tube a sample of mixture is taken and kept aside for few minutes to check if the glycerin is forming a separate layer in the bottom. If the glycerin forms a separate layer in the test tube means process is complete. Stop the reaction and Pour the mixture in the separating flask and allow settling for at least 60 minutes for the glycerin to form a separate layer as shown in the figure 1 , figure 2 and figure 3.

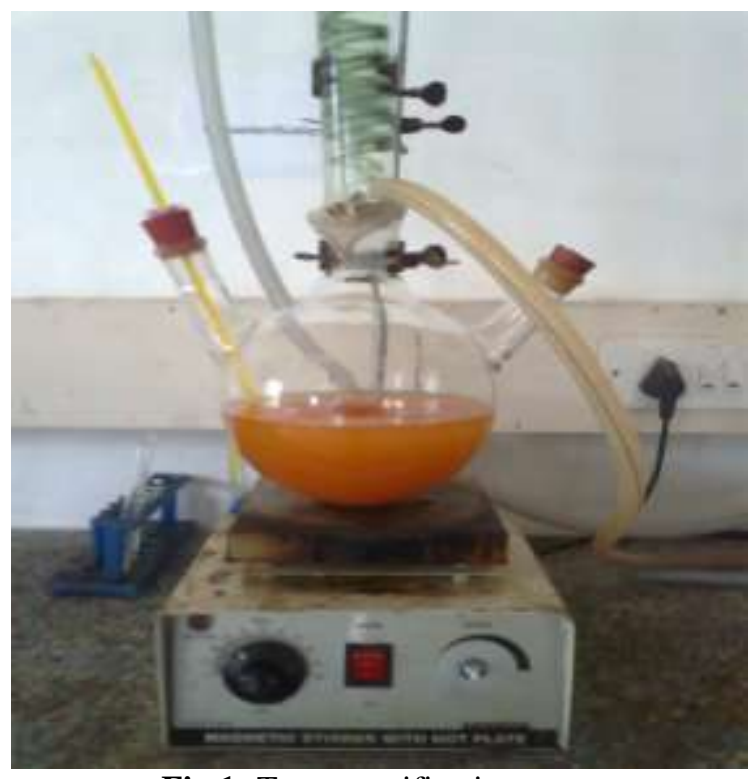

Fig 1: Transesterification setup

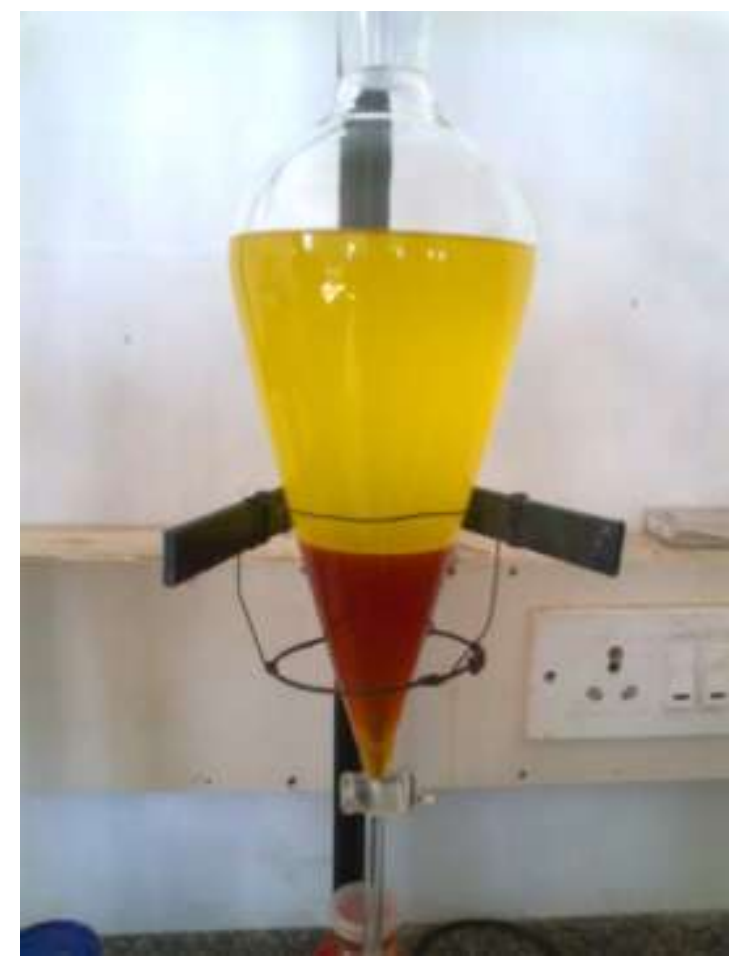

Fig 2: Formation of Glycerin Layer

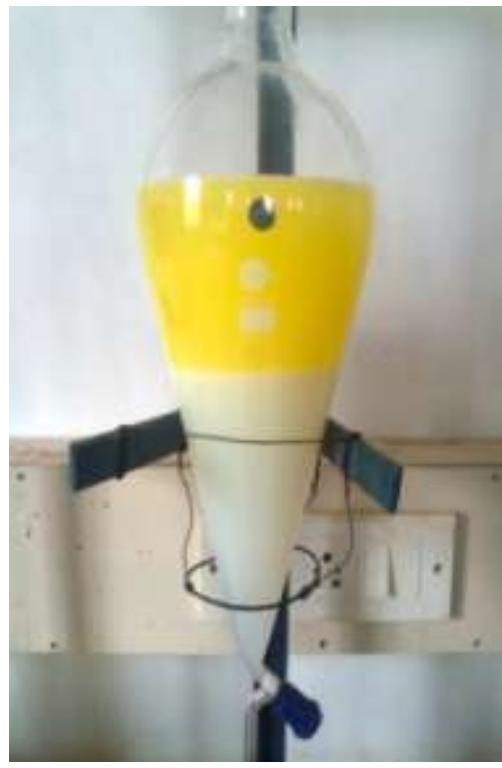

Fig 3: Water wash

\section{EXPERIMENTAL PROCEDURE}

\subsection{Fuel Properties}

Crude waste chicken fat oil filtered to remove the impurities and then transesterified by the above said method. The chicken fat methyl ester fat contained no suspended particle but had an undesirable smell. The color was transparent, pale yellow. The fuel properties were tested in ISO Certified center.

\subsection{Experimental Setup}

The experiment is conducted on a single cylinder, 4 stroke, diesel engine maintained at a constant speed of $1500 \mathrm{rpm}$ and 210 bar for biodiesel and its blends B20, B40, B60, B80 and $\mathrm{B} 100$ at various loads. The performance parameters such as BSFC, BSEC, BTE, EGT and emissions characteristics like $\mathrm{HC}, \mathrm{CO}, \mathrm{CO}_{2}$ and $\mathrm{NO}_{\mathrm{X}}$ are evaluated and the results are compared with diesel performance.

Table 1: Specification of engine

\begin{tabular}{|l|l|l|}
\hline $\begin{array}{l}\text { SL. } \\
\text { NO }\end{array}$ & PARAMETERS & SPECIFICATION \\
\hline 1 & Type & TV 1 (kirloskar) made) \\
\hline 2 & Nozzle opening pressure & 200 to 225 bar \\
\hline 3 & Governor type & $\begin{array}{l}\text { Mechanical centrifugal } \\
\text { type }\end{array}$ \\
\hline 4 & Number of cylinders & Single cylinder \\
\hline 5 & Number of strokes & Four stroke \\
\hline 6 & Fuel & Diesel \\
\hline 7 & Compression ratio & $16.5: 1$ \\
\hline 8 & Cylinder diameter (Bore) & $80 \mathrm{~mm}$ \\
\hline 9 & Stroke length & $110 \mathrm{~mm}$ \\
\hline
\end{tabular}




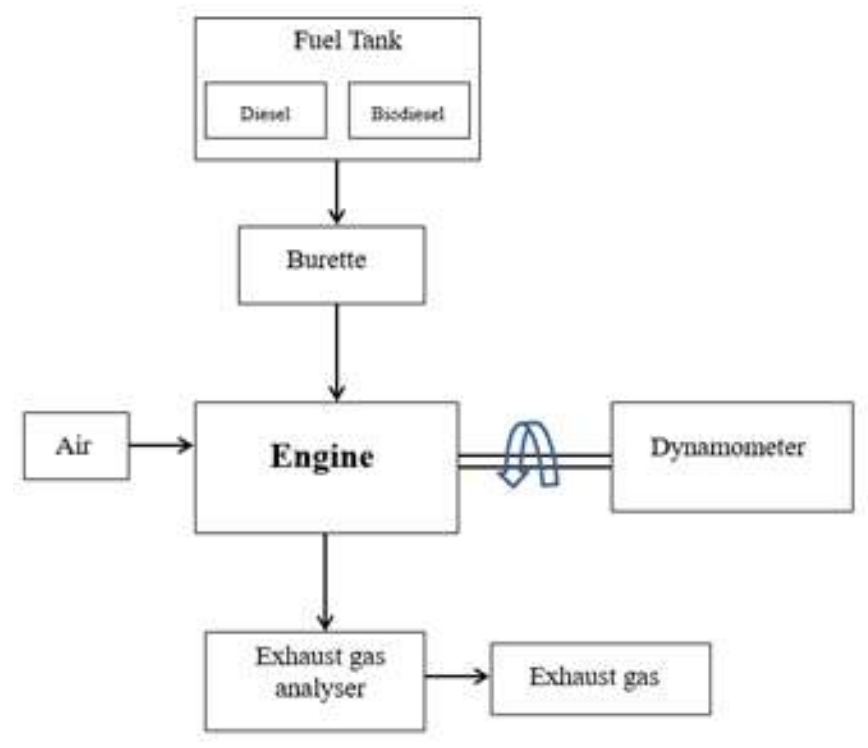

Fig 4: Experimental set up

\section{RESULTS AND DISCUSSION}

\subsection{Transesterification}

The fuel properties of CFME (chicken fat methyl esters) along with chicken fat oil and diesel are listed in table 2. CFME biodiesel and diesel comparatively had common fuel properties.

Table 2: Properties of chicken fat bio-diesel and diesel

\begin{tabular}{|l|l|l|}
\hline Properties & CF Biodiesel & Diesel \\
\hline Density $\mathrm{Kg} / \mathrm{m}^{3}$ & 885 & 850 \\
\hline Specific gravity & 0.885 & 0.850 \\
\hline $\begin{array}{l}\text { Viscosity at } 40^{0} \mathrm{C} \\
\mathrm{mm}^{2} / \mathrm{s}\end{array}$ & 4.386 & 2.6 \\
\hline $\begin{array}{l}\text { Calorific Value } \\
\mathrm{KJ} / \mathrm{kg}\end{array}$ & 39807 & 42800 \\
\hline Flash Point ${ }^{0} \mathrm{C}$ & 129 & 56 \\
\hline Fire Point ${ }^{0} \mathrm{C}$ & 141 & 64 \\
\hline
\end{tabular}

\subsection{Engine Performances}

Performance of engine with chicken fat bio-diesel was evaluated in terms of brake specific fuel consumption, brake specific energy consumption, thermal efficiency and exhaust gas temperature at different loading conditions of the engine.

\subsubsection{Brake Specific Fuel Consumption (BSFC)}

The variation in BSFC with load for different blends of fuels is presented in figure 5. Observed that higher BSFC for all blends than that of diesel. The main reason for this was the heat content for B100 is lower than diesel. Comparable trends of BSFC with increasing load in different biodiesel blends were also reported by other researchers $[8,9]$ while testing biodiesels obtained from other oils.

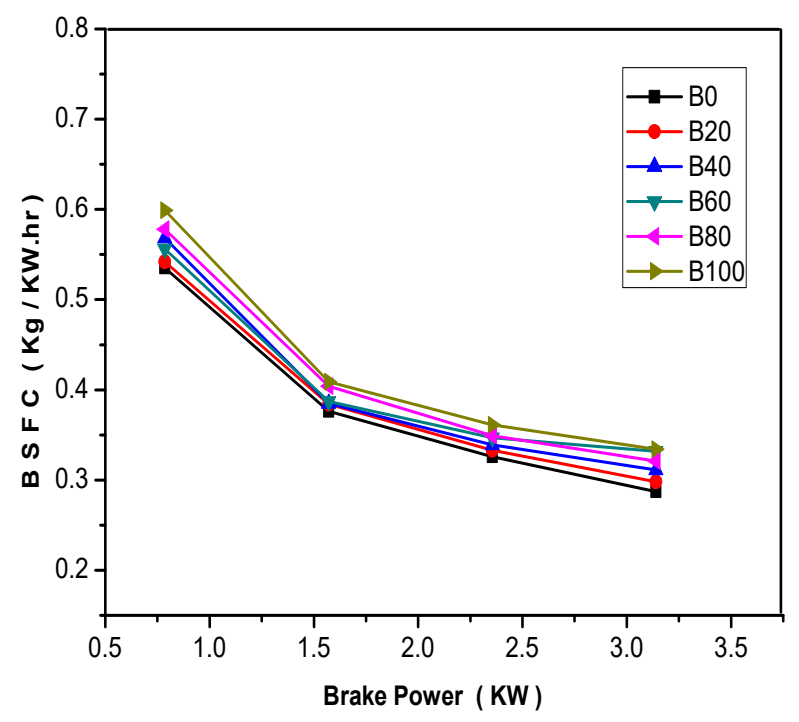

Fig 5: Comparison of BSFC with BP chicken fat bio-diesel and its blends with diesel

\subsubsection{Brake Specific Energy Consumption}

Figure 6 shows the variation in BSEC with load for biodiesel blends of fuels. It is noticed that in different blends of biodiesel, BSEC decreased drastically with increase in percentage of load for all blends of biodiesel.

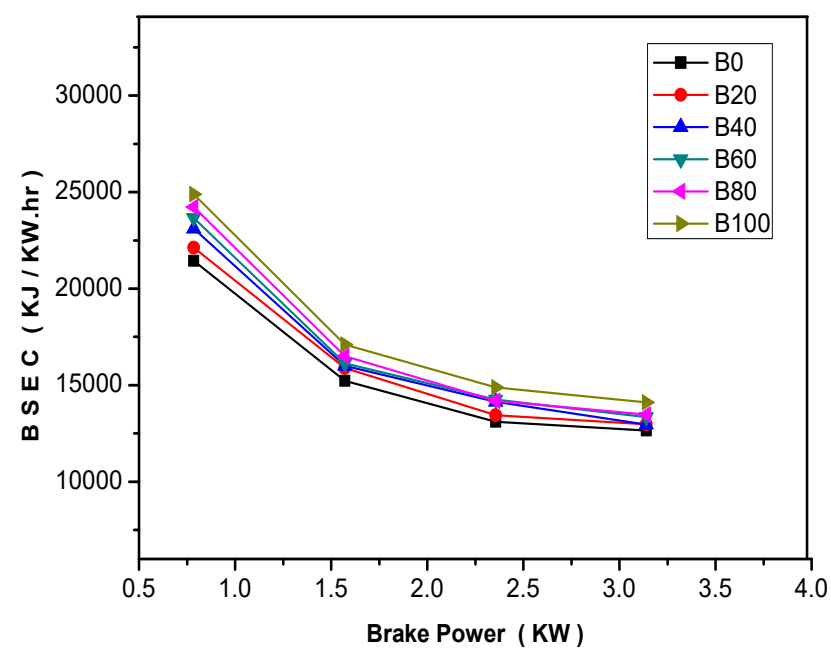

Fig 6: Comparison of BSEC with BP for chicken fat biodiesel and its blends with diesel.

\subsubsection{Brake Thermal Efficiency (BTE)}

BTE with load for different blends of fuels is shown in figure 7. It is noticed that, in all cases, BTE increased with increase in load for biodiesel blends. This was because of reduction in heat loss and increase in power with increase in load. The B20 (30.85\%) was the maximum BTE observed and which is higher0than diesel. The less BTE for B40, B60 and B80 compared to diesel were obtained. The resulted lower BTE obtained could be due to reduction in calorific value and increase in mass of fuel consumption as compared to B20. Hence, B20 blend was selected for further investigations and long-term operation as an optimum blend. 


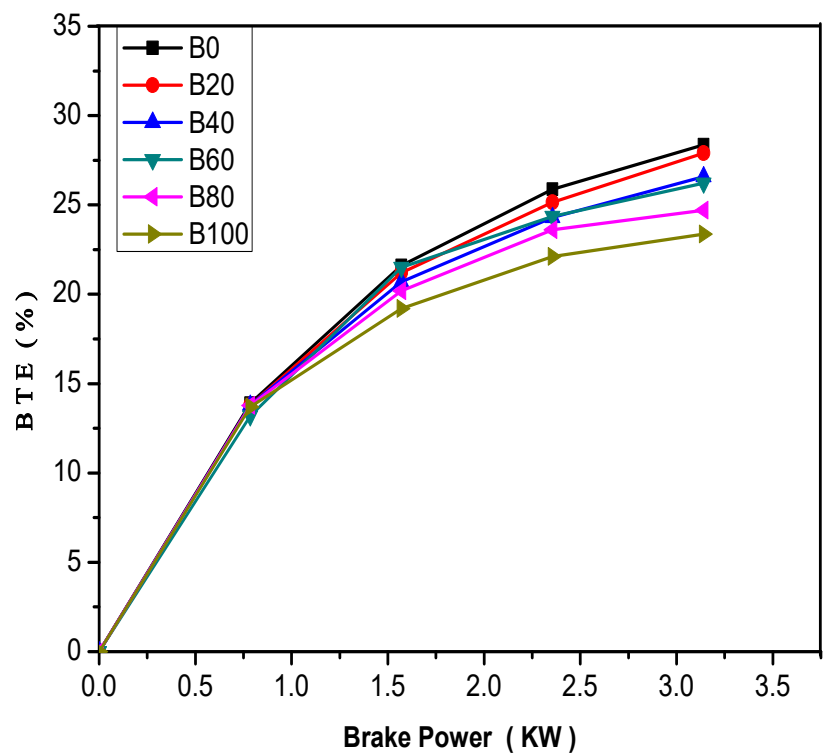

Fig 7: Comparison of BTE with BP for chicken fat bio-diesel and its blends with diesel

\subsubsection{Exhaust Gas Temperature (EGT)}

The variations of exhaust gas temperature with engine loading are shown in figure 8 . Generally, with increase in engine loading the EGT increased for all the blends of fuel tested. The mean temperature increased linearly from $182^{\circ} \mathrm{C}$ at no load to full load at $410^{\circ} \mathrm{C}$. It was found that EGT increases with the increasing blends of biodiesel.

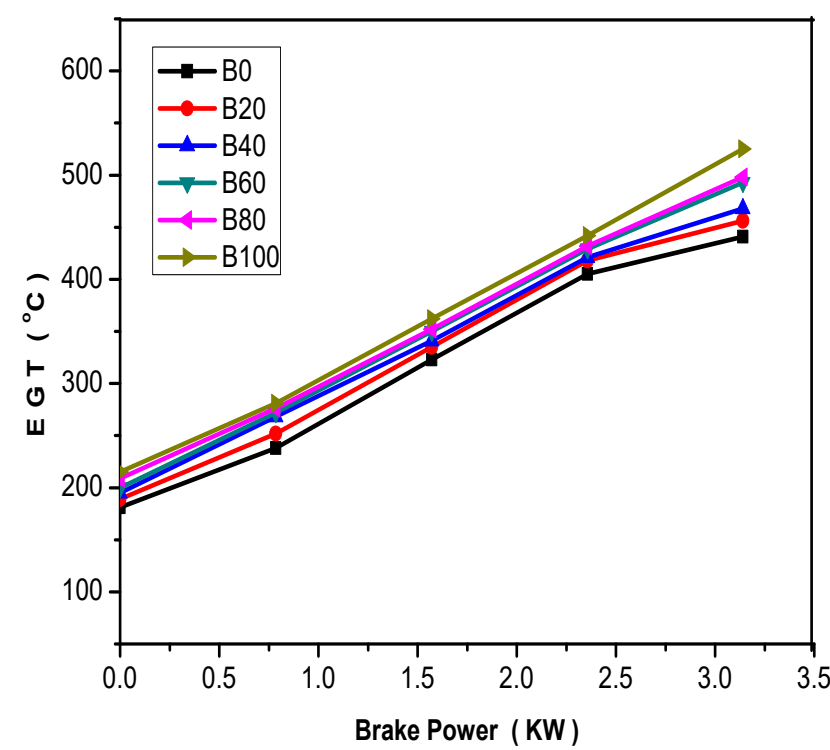

Fig 8: Comparison of EGT with BP for chicken fat bio-diesel and its blends with diesel

\subsubsection{Carbon Monoxide}

The variations in $\mathrm{CO}$ are shown in Fig. 9. It is observed that the emission of carbon monoxide decreases with increase in blends of biodiesel. It is due to complete combustion of the fuel.

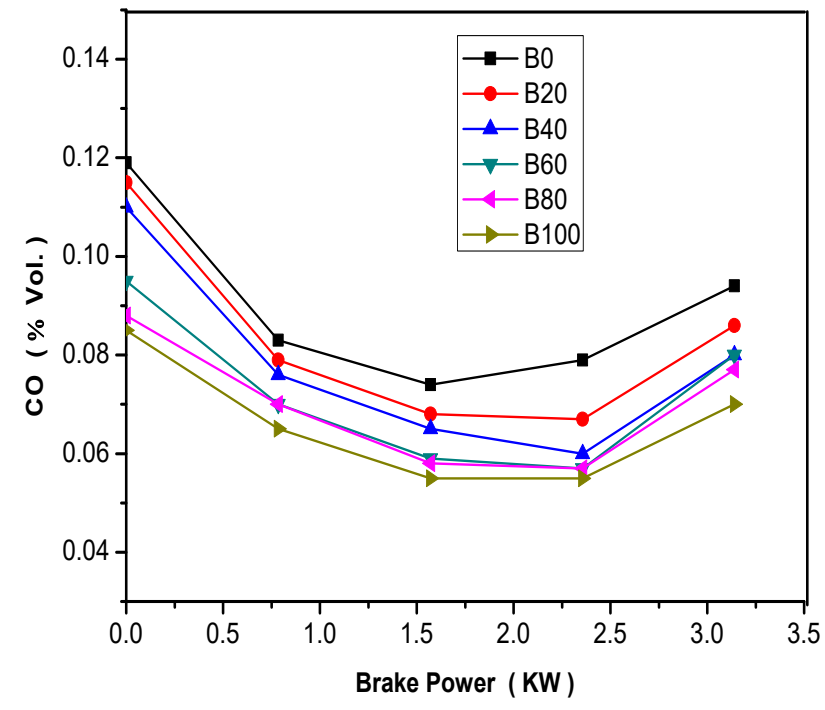

Fig 9: Comparison of CO with BP for chicken fat bio-diesel and its blends with diesel.

\subsubsection{Hydrocarbons}

Figure10 shows that, there is a substantial decrease in the hydrocarbon emission level with blends of biodiesel as compared to pure diesel operation. Similar results were also obtained by researchers for different biodiesels $[10,11]$

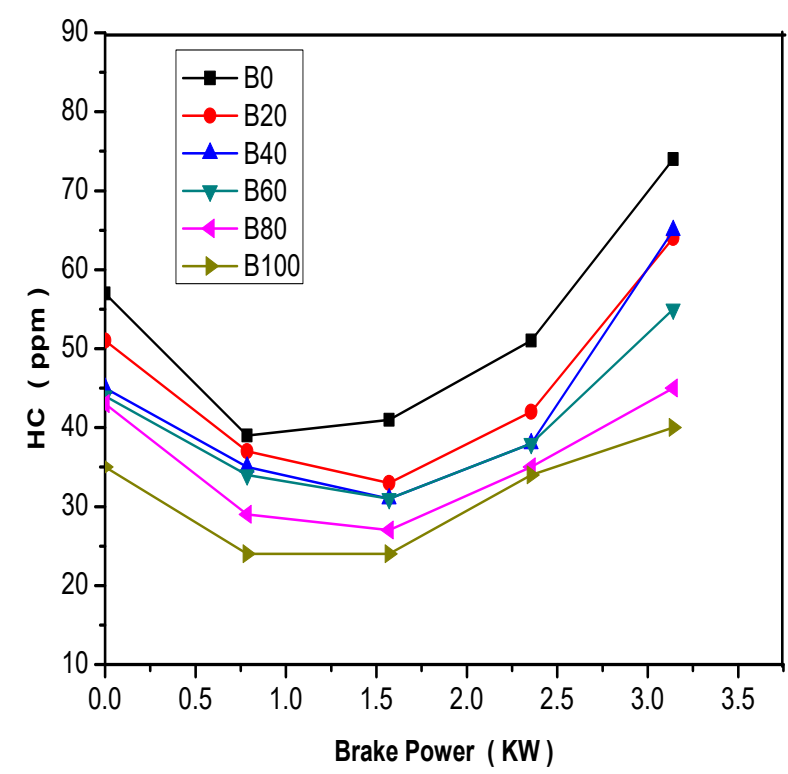

Fig 10: Comparison of $\mathrm{HC}$ with $\mathrm{BP}$ for chicken fat bio-diesel and its blends with diesel

\subsubsection{Oxides of Nitrogen $\left(\mathrm{NO}_{\mathrm{X}}\right)$}

$\mathrm{NO}_{\mathrm{x}}$ emission is shown in Fig. 11. As blend percentage increases NOx emission also increased. The NOx emission increases with increase in load for diesel, blends of biodiesel when compared to pure diesel. 


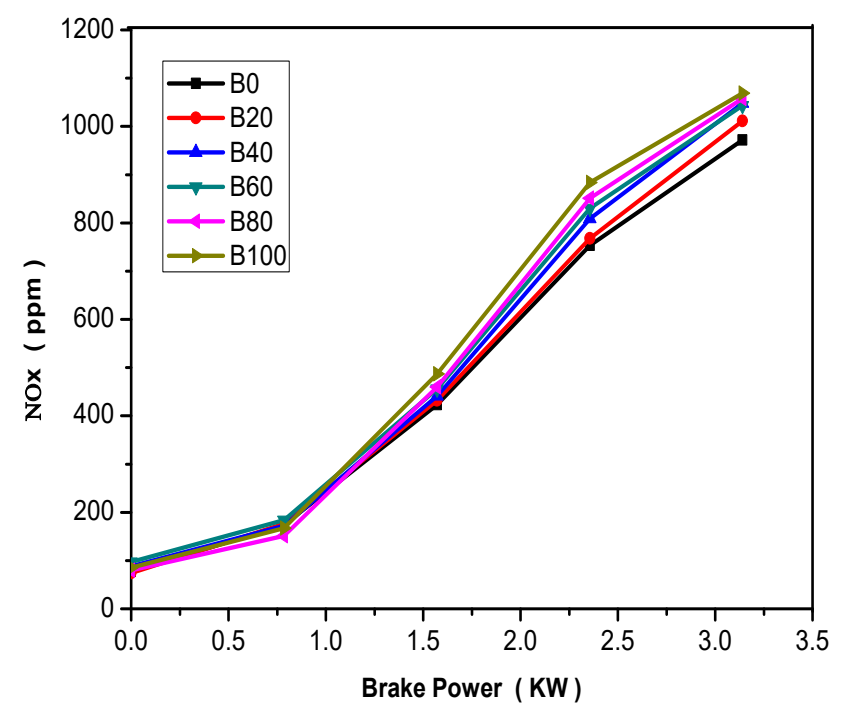

Fig 11: Comparison of NOx with BP for chicken fat biodiesel and its blends with diesel

\section{CONCLUSION}

The following conclusions were drawn form results obtained with this study,

$>$ Chicken fat bio-diesel can be recommended as an alternative fuel to diesel fuel in terms of fuel properties and exhaust emission characteristics.

$>$ BSFC for blends of fuel is higher than the diesel. The blends $\mathrm{B} 80$ and $\mathrm{B} 100$ have shown higher BSFC.

$>$ The maximum thermal efficiency for B20 (30.85\%) which was close to that of diesel and less for B40, B60, $\mathrm{B} 80$ and $\mathrm{B} 100$.

$>$ The EGT increased with the concentration of biodiesel blend i.e. higher the percentage of CFME.

$>$ Increase in the EGT of a biodiesel-fueled engine led to increase in NOx emissions for B100.

$>$ The reduction in $\mathrm{CO}$ and $\mathrm{HC}$ was less with the addition of biodiesel for the blends of fuel.

\section{REFERENCES}

[1] Raheman H, Ghade SV. Performance of compression ignition engine with Mahua (Madhuca indica) biodiesel. Fuel 2007;86:2568-73.

[2] Ramdas AS, Jayraj S, Muralidharan C. Use of vegetable oils as Internal combustion engine fuels-A review. Renewable Energy 2004;29:729-42.

[3] Raheman $H$. of Diesel engine emissions and performance from blends Karanja methyl ester and diesel. Elsevier. Biomass Bioenerg 2004;27: 393-7.

[4] Canakci M. Combustion characteristics of a turbocharged DI compression ignition engine fueled with petroleum diesel fuels and biodiesel. Bioresource Technology 2007;98:1167-75.

[5] Kondamudi N, Strull J, Misra M, Mohapatra SK. A green process for producing biodiesel from feather meal. J. Agric. Food Chem. 2009;57:6163-66.

[6] Dale N. True metabolizable energy of feather meal. J. Appl. Poult. Res. 1992;1:331-34.
[7] Canakci M, Van Gerpen JH. Biodiesel production via acid catalysis. Trans. of ASAE 1999;42(5):1203-10.

[8] Mustafa Canakci a,b, ${ }^{*}$, Ahmet Necati Ozsezen a,b, Erol Arcaklioglu c, Ahmet Erd-Expert Systems with Applications 36 (2009) 9268-9280: Elsevier"

[9] Banapurmath NR, Tewari PG, Hosmath RS. Performance and emission characteristics of a DI compression ignition engine operated on Honge, Jatropha and sesame oil methyl esters. Renewable Energy 2008;33: 1982-8.

[10] Performance and Emission Characteristics of a Kirloskar HA394 Diesel Engine Operated on Mahua Oil Methyl Ester -Sharanappa Godiganur, Ch. Suryanarayana Murthya and Rana Prathap Reddyb"Thammasat Int. J. Sc. Tech., Vol. 15, No. 3, JulySeptember 20

[11] H. Raheman .V. Ghadge Performance of compression ignition engine with mahua (Madhuca indica) biodiesel; Fuel 86 (2007) 2568-2573. 